\title{
1 Life cycle assessment of a circular, urban mushroom farm
}

2 Erica Dorr, Maximilien Koegler, Benoit Gabrielle, Christine Aubry

3 Abstract

$4 \quad$ Modern food systems incur many environmental impacts, which can be mitigated by the

5 application of circular economy principles, such as the closing of material and energy loops and

6 the upcycling of waste products. Mushroom farming provides a relevant case in this direction

7 because organic waste can be used for substrate as an input in the cultivation process, which

8 produces valuable outputs such as edible foodstuffs and soil amendment. Few studies evaluate

9 the actual environmental impacts of circular food production systems and assess their efficacy

10 with respect to more linear alternatives. To address this research gap, we quantified the

11 environmental impacts of a circular, urban mushroom farm next to Paris, France. We used life

12 cycle assessment to study the production of $1 \mathrm{~kg}$ of fresh oyster mushrooms (Pleurotus

13 ostreatus), from the generation of substrate materials through delivery to the distribution

14 center. Our goals were to quantify the environmental impacts of a novel type of food

15 production system, to find the aspects of production that contribute most to these impacts, and

16 to assess the advantages and disadvantages of circular economy for this case study. In terms of

17 climate change impact, the product system emitted $2.99-3.18 \mathrm{~kg} \mathrm{CO}$-eq./kg mushroom, and on-

18 farm energy use was the top contributor to all impact categories except land use. Surprisingly,

$1931 \%$ of the climate change impacts came from transport throughout the supply chain, despite

20 the local nature of the farm. Circular economy actions helped optimize the environmental

21 performance by minimizing impacts from the use of materials, which were mostly upcycled. This 
22 suggests that further improvements could be made by reducing energy consumption on the

23 farm or by making the transport schemes more efficient, rather than continuing to focus on the

24 type and source of materials used. This circular, urban farm had similar climate change impacts

25 to classical, more linear systems, but these impacts could be largely reduced by implementing

26 appropriate actions. These were identified and discussed with the farmers, factoring in their

27 feasibility.

28 Keywords: life cycle assessment; mushroom; circular economy; urban agriculture; industrial

29 ecology; sustainable food systems

\section{1. Introduction}

32 The current food and agriculture system is considered by many to be environmentally

33 unsustainable due to its substantial emissions, pollution and resource consumption (Campbell

34 et al., 2017). Alternative food systems that ensure the well-being of people and the

35 environment have been put forward (Kloppenburg et al., 1996), which call for improvements in

36 the environmental sustainability compared to the mainstream systems. These can come from

37 extensive and small scale farming, local food production, short supply chains, and circular

38 economy (Forssell and Lankoski, 2015; Kiss et al., 2019).

39 The latter, circular economy, is particularly relevant in current research, practice, and policy, as

40 evidenced by its major role in the European Green Deal and cities' action plans (European

41 Commission, 2020; Mairie de Paris, 2017). Circular economy is a principle that comes from the 
42 discipline of industrial ecology, which generally aims to design industrial or human-made

43 systems using principles from ecology as a means to attain sustainability (Tóth, 2019). The

44 concept of circular economy emerged from the work of Boulding (1966) as a framework for

45 managing limited resources in a closed system, such as the Earth, and it has gained attention in

46 recent years from academics, policy makers, and the private sector (Merli et al., 2018). Circular

47 economy evokes a departure from linear economies based on "take-produce-consume-discard"

48 models, which assume unlimited resources and waste disposal facilities (Jurgilevich et al., 2016;

49 Merli et al., 2018). Instead, circular economy focuses on closing material, energy and nutrient

50 loops through "reducing, actively reusing, recycling and recovering materials" (Kirchherr et al.,

51 2017). The principles of circular economy are not new, and this paradigm builds upon previous

52 concepts relating to cleaner production, closing loops, and reduce-reuse-recycle (Tóth, 2019).

53 Still, it goes beyond these concepts by considering them in multiple dimensions of sustainability,

54 and by explicitly introducing the notion of full circularity. Scientific studies of circular economy

55 have been done at the macro- (city, region, country), meso- (industrial park) and micro-

56 (consumer, product, company) levels, and are often concerned with the environmental and/or

57 economic sustainability of waste management and the agri-food sectors (Ghisellini et al., 2016;

58 Kirchherr et al., 2017; Merli et al., 2018). Although circular economy can have holistic benefits

59 to environmental, economic and socially sustainable development, we chose here to focus on

60 the environmental dimension (Fassio and Tecco, 2019).

61 Agriculture has been identified as a relevant topic for implementation of circular economy due

62 to its environmental sustainability issues, large amount of waste production, and important

63 nutrient flows (Fassio and Tecco, 2019). A review of 40 circular practices from case studies in 
64 the agro-food sector found that the main circular practices employed relate to optimization,

65 looping, and regeneration (Fassio and Tecco, 2019). Here, optimization focuses on removing

66 waste from production systems by transforming materials regularly considered as waste into

67 valuable inputs to another system without losing value, otherwise known as upcycling.

68 Regeneration refers to a shift to renewable energy and materials, and looping aims to keep

69 materials in closed loops (MacArthur et al., 2015). Within the food system, this can be

70 implemented by utilizing food byproducts and waste to recycle nutrients, avoiding generation of

71 waste altogether, and shifting diets towards foods that can be produced with minimum inputs

72 (Jurgilevich et al., 2016). Collaboration between the food production and waste management

73 sectors is especially important to keep nutrients and organic matter in productive loops rather

74 than discard them as waste through landfilling or incineration.

75 Mushroom farming is a particularly appropriate activity to demonstrate the potential symbioses

76 of circular economy. Many cultivated fungi naturally cycle organic matter and nutrients by

77 decomposing organic waste and yielding edible mushrooms. The organic waste that mushrooms

78 are grown on is transformed into a nutrient rich soil amendment that is rich in organic carbon,

79 called spent mushroom substrate (SMS) (Grimm and Wösten, 2018; Stamets, 2000). This allows

80 for symbioses in the inputs to the system, whereby mushroom farms can take up waste streams

81 of materials such as straw and manure to give value to the waste and extract their remaining

82 nutrients and organic matter (Sánchez, 2010). For example, Chance et al. (2018) present a

83 mushroom farm that is highly symbiotic with other businesses in an industrial park, through

84 upcycling waste products from beer brewing and coffee roasting. On the output side, SMS,

85 which is essentially composted waste, has many uses as soil amendment, animal feed, biofuel 
material, wastewater treatment, and packaging material (Grimm and Wösten, 2018; Mohd

87 Hanafi et al., 2018). Oyster mushrooms (Pleurotus spp.) have been shown to successfully grow

on waste substrates that do not have other common recycling paths, including grape marc from

wineries, waste from olive oil mills, and coffee ground waste recovered after the brewing phase

(Koutrotsios et al., 2018; Murthy and Madhava Naidu, 2012). Spent coffee ground (SCG) use is

91 unique because it is an urban waste. Its upcycling by urban and peri-urban mushroom farms

92 would allow for a closed loop system with minimal distance between collaborating actors

93 (waste collection, mushroom production and consumption points), and could place the

94 production near the consumers. Furthermore, an estimated six million tons of SCGs are

95 generated annually worldwide, making up between $16-35 \%$ of the food waste from restaurants,

96 cafes and gas stations (Silvennoinen et al., 2015; Tokimoto et al., 2005). Although they can be

97 upcycled by other methods, such as for animal feed, antioxidant extraction, and biofuel, they

98 are typically not valorized and are treated in the regular waste stream (Kovalcik et al., 2018).

99 Evaluations of circular economy food production are necessary to test the actual environmental

100 advantages of circularity, and to help design optimally sustainable systems. In a review of

101 performance evaluations in this context, Sassanelli et al. (2019) found that life cycle assessment

102 (LCA) was the most commonly used method. LCA is a standardized methodology and tool that

103 models and evaluates systems through their entire life cycle, from extraction of raw materials

104 through disposal (ISO 14040, 2006). Environmental LCA considers the outputs associated with

105 the flows of material and energy in the life cycle of a product, and quantifies the related

106 environmental impacts. Several LCAs of circular food production systems focus on using waste

107 as an input (Dorr et al., 2017; Llorach-Massana et al., 2017), but to the best of our knowledge, 
no studies focus on mushroom production. Several studies perform LCAs for current food systems and, based on the outcomes, make recommendations for implementing circular

110 strategies to reduce environmental impacts (Krishnan et al., 2020; Pagotto and Halog, 2016).

111 Comparison between circular and conventional, linear systems points to mixed results,

112 indicating that circular systems should not be considered better by default. For example, Fan et

113 al. (2018) assessed pig farming in a circular agriculture system that also included hay, fish,

114 dragon fruit, mushroom, biogas, and compost production. They found that environmental

115 impacts were higher in the circular system than the traditional system by an average of $43 \%$

116 across 11 impact categories, and that removing some actors from the large network could

117 improve environmental sustainability. Strazza et al. (2015) compared the production of

118 conventional fish feed for aquaculture, made with crops and fish, with a circular option of fish

119 feed derived from food waste, and found that the circular option had lower climate change

120 impacts and energy and water demand by an average of approximately $60 \%$. Also assessing the

121 upcycling of food waste to agriculture, Oldfield et al. (2017) studied the valorization of tomato

122 processing waste for annual preparation of agricultural soils (in a process called biosolarization),

123 and found this circular option to be less environmentally impactful than the business-as-usual

124 system by $20-23 \%$. More LCA case studies in different contexts are needed to evaluate the

125 actual contributions of circular economy agriculture to environmental sustainability.

126 In parallel, a number LCAs of typical mushroom production have been performed. Gunady et al.

127 (2012) evaluated button mushroom (Agaricus bisporus), strawberry, and lettuce production

128 using survey data from farmers in Australia, with a cradle-to-market scope. They found that

129 most climate change impacts in the mushroom systems came from the pre-farm stage, from 
deliveries of materials for substrate including compost and peat (common substrate materials

131 for button mushroom farming, as opposed to oyster mushrooms which can grow on organic

132 waste). Leiva et al. (2015a) collected data from a button mushroom farm in Spain and

133 performed a cradle-to-farm gate LCA. They found that on-farm energy use was the main driver

134 for all impact categories. Specifically, this was from indoor climate control for most impacts, and

135 from application of compost for climate change impacts. Robinson et al. (2018) performed a

136 cradle-to-farm gate LCA of button mushroom production in the USA. They modeled a typical

137 farm using survey responses from 22 mushroom farmers. They also found that on-farm energy

138 use was the major contributor to several impact categories, and cited use for climate control,

139 trucks, and machinery. Unlike the first two studies mentioned, Robinson et al. (2018) included

140 emissions from the composting process that created substrate to cultivate mushrooms on, and

141 found that it had an important contribution to climate change impacts (23\%). The only LCA we

142 found of oyster mushroom production was by Ueawiwatsakul et al. (2014), who collected data

143 from 31 farms in Thailand and used a cradle-to-farm gate scope. The most impactful processes

144 were emissions from burning firewood and fuel to sterilize the substrate, and transport of

145 substrate materials (rice bran and sawdust). The small set of mushroom LCAs show variable CC

146 results, from $2.13-5.0 \mathrm{~kg} \mathrm{CO} 2$ eq. / kg mushroom, suggesting the need for further research into

147 this type of farming.

148 To help fill the knowledge gaps in circular agriculture and mushroom farming environmental

149 impacts, we conducted an environmental LCA of a circular, urban oyster mushroom farm in a

150 town neighboring Paris, France. Our goals were first to quantify the environmental impacts of

151 this type of farm and find the most impactful phases of production. Our second goal was to 
152 investigate explicitly the circular economy aspects of the farm to understand their positive and

153 negative contributions to environmental impacts. The farm case study grows oyster mushrooms

154 (Pleurotus ostreatus) using SCGs collected from Paris as the bulk material for the substrate, in

155 the place of typical substrate materials consisting of agricultural co-products such as straw

156 (Sánchez, 2010). The waste product SMS is sold to local farmers who use it as a substrate

157 amendment, and the mushrooms are delivered to a nearby distribution center in the wholesale

158 market of Rungis and consumed mostly in Paris.

\section{2. Methods}

\subsection{Case study description}

161 The mushroom farm is situated on $1000 \mathrm{~m}^{2}$ of land next to Paris in the Yvelines administrative

162 department in France, and sources many materials from and delivers all of its product to the

163 Paris region. Maintaining short supply chains and reusing urban waste to promote a circular

164 economy are important to the farm's mission. This is evidenced first by the upcycling of SCGs. In

1652018 alone the farm used approximately 30 tonnes of SCGs, diverting them from the municipal

166 waste stream of Paris while extracting their remaining organic matter and nutrient contents.

167 The farm's second main contribution to a circular economy comes from waste management,

168 whereby SMS is sold to local farmers who pick it up from the farm and either compost it or

169 directly spread it to agricultural fields as both an organic amendment and a fertilizer. It has even

170 been used by farmers in the urban agriculture network of Paris and shown to be a soil

171 amendment high in organic matter and nutrients (Grard et al., 2015). 
172 The mushroom farm represents a short food supply chain because the major input material

173 (SCGs) is sourced locally (about $35 \mathrm{~km}$. away), the product is sold and consumed locally (about

$17445 \mathrm{~km}$. away), and there are a reduced number of intermediaries between producer and

175 consumer. The delivery of mushrooms is done daily by an employee who passes near the

176 market every day on his commute home, and so involves frequent deliveries and small volumes.

177 SCGs are delivered to the farm weekly, with the delivery truck returning empty and the

178 frequency of deliveries limited by the amount that they can store, and the risk that large stocks

179 of SCGs sitting on the farm are prone to fungal contamination. Frequent trips with low volumes

180 of material is a regular characteristic of short supply chains, and can be economically and

181 environmentally inefficient (Brunori et al., 2016; Schlich and Fleissner, 2005).

182 The cultivation of mushrooms follows typical growing practices, requiring approximately 2

183 months to fruit after being inoculated with mycelium (Sánchez, 2010). The substrate is made up

184 mostly of SCGs, along with wood chips, agricultural lime, mycelium-inoculated rye seeds, and

185 municipal tap water. The substrate materials are mixed, pasteurized using a large autoclave, and

186 inoculated with mycelium, after which the mix is placed in $32 \mathrm{~L}$ plastic bags. Next, in the

187 cultivation stage, bags are incubated for about 2 weeks at $70 \%$ relative humidity and $17^{\circ} \mathrm{C}$ and

188 then spend 7 weeks at $93 \%$ relative humidity and $16.5^{\circ} \mathrm{C}$. During this stage, contamination by

189 competing fungi and bacteria is a major problem, leading to losses of nearly $25 \%$ of the bags of

190 substrate prepared. Harvest is done manually throughout these 7 weeks, and occurs several

191 times before the substrate is considered spent. In 2018 a total 8,728 kg of mushrooms were

192 harvested, and during the study period the harvest was $1,253 \mathrm{~kg}$ of mushrooms. The

193 mushrooms are packaged in small wooden crates ( $2 \mathrm{~kg}$ per crate) and delivered to the Rungis 
194 wholesale food market south of Paris, where they can be sold to local grocery stores and

195 restaurants. The Rungis market is an essential food distribution source for Paris, with $40 \%$ of all

196 food consumed in the city passing through Rungis (Mairie de Paris, 2016). The SMS is sold to

197 local farmers who pick it up at the mushroom farm and apply it as a soil amendment.

2.2. Life cycle assessment

\subsubsection{Goals and scope}

200 The main goals of this LCA were to assess several environmental impacts of circular, urban

201 mushroom cultivation, identify the aspects of the system that contribute the largest impacts,

202 and evaluate the role of circular practices in the environmental performance. Comparisons to

203 other mushroom LCAs are also presented. The functional unit was $1 \mathrm{~kg}$ fresh weight of oyster

204 mushrooms, produced over a 2-month period at the end of 2018. Use of data from a 2 month

205 period was justified because, although there are annual variations in production, they are

206 related to holidays and social factors that affect resource use and food production, rather than

207 climatic conditions. For example, there is lower mushroom production in July and August

208 because of summer holidays, but there is proportionally lower energy and water consumption

209 because of the decision to reduce production. A process-based, attributional LCA was

210 performed, with a cradle-to-market scope. The system boundary is illustrated in Figure 1 and

211 includes the extraction of raw materials and energy use used in the foreground and background

212 of mushroom growing, delivery to the distribution center, and the waste treatment of

213 consumed materials. Construction and waste treatment of machinery and infrastructure were

214 excluded due to their assumed longevity and relatively small impacts (Martin and Molin, 2019). 
215 Delivery from the distribution center to the final consumer was excluded due to constraints on 216 data collection.

\subsubsection{Life cycle inventory}

218 Background processes were modelled using the Ecoinvent v3.5 database using the recycled

219 content system model (Ecoinvent, 2018). Electricity use was modeled using the French grid.

220 Information about foreground processes was collected from farm records, interviews about

221 farm practices, water and energy bills, and technical specifications documents for machinery

222 and purchased supplies. The life cycle inventory for mycelium production was taken from Leiva

223 et al. (2015b), using Swiss integrated rye production. The life cycle inventory, showing inputs

224 attributed per kilogram of mushroom, is compiled in Table 1, and a more detailed inventory

225 with corresponding Ecoinvent process names is included in Table A1 in the Appendix.

226 To facilitate interpretation of the results, the production system was delineated chronologically

227 into 4 life cycle stages, shown in Figure 1. The first stage was "Substrate materials" and included

228 the production and acquisition of materials to compose the substrate on which mushrooms

229 were cultivated, along with electricity from a refrigerator used to store mycelium. Next, the

230 "Substrate preparation" stage involved preparing the substrate materials through mixing, gas-

231 powered pasteurizing, and bagging, along with the plastic bags themselves. The "Cultivation"

232 stage consisted of the inputs used during the 2 month period from inoculation to fruiting and

233 harvest, such as water for cleaning rooms and maintaining humidity, and electricity from LED

234 lights and air heating/cooling. Sanitary materials were counted, including lab coats that were

235 washed and reused 5 times before disposal, and disposable gloves, hair nets and shoe covers. 
236 Steel racks that held the hanging bags were also covered here, with an assumed lifetime of 30

237 years. Finally, the "Packaging and delivery" stage included wooden crates and the transport to

238 deliver products to the distribution center, Rungis, 38 kilometers away.

\subsubsection{Allocation procedures}

240 SCGs used in the substrate were treated using the simple cut-off method (Ekvall and Tillman,

241 1997) to allocate their impacts to the system that was directly responsible for them, such as the

242 café that used them to make coffee. As a result, the only burdens the mushroom farm is

243 responsible for come from the transport of the grounds from their place of use to the farm site.

244 The farm produces a co-product along with oyster mushrooms: SMS. Allocation between co-

245 products of a system is a notoriously debated issue in the LCA community, as several options

246 exist but there is no consensus on which approach is best (Finkbeiner et al., 2014). System

247 expansion with avoided burdens is a common and appropriate method, but it can require

248 assumptions that are highly uncertain. According to this method, the system is expanded to

249 include the alternative product that is displaced (or avoided) by the co-product of the system. It

250 is assumed that the system's co-product replaces the alternative product, resulting in negative

251 (or avoided) production of the alternative product and negative environmental impacts

252 (Vadenbo et al., 2017). However, this option would be problematic here because SMS provides

253 many functions and does not clearly replace just one product. It is used as a substitute for

254 composts, mineral fertilizer, or potting soil, and the effect of substituting for each of these

255 products is extremely variable. To avoid making assumptions about such sensitive processes,

256 economic allocation was used to distribute impacts based on the annual revenue from SMS and 
oyster mushrooms. We chose economic allocation because it appropriately represented the

258 relationship and value partition between mushrooms and SMS. For example, mass allocation

259 would not be appropriate here because the SMS produced has almost six times the mass of the

260 mushrooms produced while carrying only a fraction of the market value of mushrooms. Thus, it

261 appears inappropriate to assign SMS six times more impact than mushrooms. Accordingly,

262 mushroom production at the farm was allocated $85 \%$ of the environmental impacts.

\subsubsection{Carbon sequestration from SMS}

264 The mushroom farm transforms a large amount of SCGs (30.3 tonnes in 2018) into SMS (51.3

265 tonnes fresh weight, 22.0 tonnes dry weight in 2018), which is used as a soil amendment. The

266 SMS at this farm contains $86 \%$ organic matter (dry weight), and a significant portion of this is

267 organic carbon (43\%, according to Paredes et al. (2009)) that is immobilized in the soil and

268 sequestered, avoiding the emission of $\mathrm{CO}_{2}$ to the atmosphere. Part of this carbon sequestration

269 benefit is attributed to the mushroom production, according to mass allocation between the co-

270 products SMS and mushrooms ( $85 \%$ and $15 \%$ by mass, respectively), unlike allocation of impacts

271 of inputs which was done economically. According to measurements of SMS characteristics

272 from the farm and values in the literature (Medina et al., 2012; Paredes et al., 2009), the

273 amount of $\mathrm{CO}_{2}$ eq. per kilogram of mushroom that was sequestered in the soil rather than

274 emitted to the atmosphere was calculated (see details in Appendix 1). The amount of $\mathrm{CO}_{2}$

275 emissions avoided was entered as a negative emission of $\mathrm{CO}_{2}$ to air in the SimaPro modelling

276 software. Climate change results are presented with and without this sequestered carbon term. 
278 The impacts discussed in this study are climate change (CC), non-renewable energy demand 279 (ED), water depletion (WD), land use (LU), and freshwater eutrophication (FE). These impact 280 categories were chosen because they are important agricultural-related burdens. Additionally, 281 they capture the food-energy-water nexus, which is an increasingly prevalent conceptual 282 framework that highlights the interdependency of these essential resources that have large 283 consumption and are vulnerable in cities (Garcia and You, 2016). The impacts were modeled as 284 midpoint indicators using SimaPro 9.0 software and several impact assessment methods, as 285 described below.

286 CC, WD, LU and FE were modeled using the Environmental Footprint 2.0 method (European 287 Commission, 2017). The specific methods are the IPCC 2013 100-year model for CC (IPCC, 2013), 288 the EUTREND model for FE (same as the model used in ReCiPe 2008 (Goedkoop et al., 2009)), 289 the soil quality index based on LANCA for LU (Beck et al., 2010), and the AWARE method for WD 290 (Ansorge and Beránková, 2017). Although these methods were selected as the best available, 291 some of them are more accepted than others. WD and LU, for example, were given the lowest 292 recommendation level of 3, which means they are the recommended methods but should be 293 used with caution. The FE model has a recommendation level of 2, defined as needing some 294 improvements, and the CC model received a recommendation level of 1 , which is recommended 295 and satisfactory.

296 ED was modeled using the single-issue characterization method Cumulative Energy Demand 297 V1.11 (MJ), and the sum of the non-renewable fossil, nuclear, and biomass energy demand are 
used here. It is important to report ED impacts because, although they are generally related to

299 CC impacts, they are not susceptible to variation in local or regional electricity grids, which can 300 have large effects on CC results.

301 A common issue in the LCA literature is that different impact categories are reported and 302 various impact assessment models are used, rendering results difficult to compare from one 303 study to another. To address this, the results for all Environmental Footprint impact and 304 Cumulative Energy Demand categories are reported in Tables A2 and A3 in the Appendix, 305 although they are not all discussed in this paper. Additionally, results from other common 306 impact assessment methods, ReCiPe 2016 and 2008 (hierarchical, midpoint) (Goedkoop et al., 307 2009; Huijbregts et al., 2017) and CML (baseline, v4.7) (Guinée et al., 2002) are reported in 308 Tables A4, A5 and A6 in the Appendix for the purpose of comparison to future studies.

\subsection{Sensitivity Analyses}

310 Sensitivity analyses are commonly done to evaluate the significance of decisions made 311 regarding the modeling of the system. We performed two sensitivity analyses: first on the 312 electricity grid, substituting electricity mixes for neighboring countries Germany, Spain and Italy 313 - given the unique characteristics of the French mix, with a predominance of nuclear energy. 314 Next we tested the importance of our decision to use economic allocation for the co-product 315 SMS rather than system expansion with avoided burdens, because allocation is often a sensitive 316 issue in LCA. We compared our results using economic allocation to results from substituting 317 mineral fertilizer for SMS to test how sensitive the results were to this choice. Assumptions and 
318 calculations for identifying the quantity of avoided fertilizer from equivalent nutrients in SMS

319 were taken from Robinson et al. (2018).

321 We modeled alternative scenarios to assess how impacts would change if the mushroom

322 production system changed. The first involved a 50\% reduction in the frequency of delivery for

323 SCGs, mycelium, and mushrooms, with twice the volume transported each trip. This was to

324 illuminate the potential efficiency issues of transportation in this short food supply chain. It is

325 generally accepted that short food supply chains can suffer from increased environmental and

326 economic impacts from inefficiencies when shipping low volumes of food on the road, which in

327 this case is also coupled with frequent deliveries (Brunori et al., 2016).

328 The second alternative scenario tested a more typical oyster mushroom substrate: wheat straw.

329 Mushrooms can grow successfully on a wide variety of substrates, and are typically cultivated

330 on agricultural waste or byproducts such as cotton seed hulls, corn cobs, sorghum stalks, or

331 coconut shells. A common and successful material is straw (Sánchez, 2010). From this

332 perspective, the valorization of SCGs as the bulk substrate material at this case study farm is

333 unique to a commercial farm of this size, and is done because of the farmers' commitment to

334 circular economy and the opportunity of being situated nearby a large city with a high

335 concentration of coffee consumption. A comparison was made to production with a more

336 typical substrate composed largely of straw (43\% wheat straw, 53\% water, 3\% mycelium and 1\%

$\left.337 \mathrm{CaCO}_{3}\right)$. The life cycle inventory for wheat straw was taken from the Ecoinvent database, where

338 an economic-based allocation was done to distribute $7-10 \%$ of the impacts from wheat grain 
production (Nemecek and Kägi, 2007). It was assumed that all other on-farm practices and the

340 final yield remained the same. The straw was transported twice the distance as the SCGs (65 km

341 away) because it is not an urban product. It was delivered every 3 weeks, rather than every

342 week for the SCGs, because there is less risk of stocks of straw becoming contaminated.

343 The third alternative scenario investigated the effect of the overall farm yield by using the

344 maximum monthly value that the farm achieved in 2018. In agricultural LCA studies, where the

345 functional unit is related to food production, results are usually quite sensitive to the yield

346 (Notarnicola et al., 2015). Mushroom farming can have highly variable yields over time due to

347 losses from pests and infection of substrate (Stamets, 2000), and indeed the case study farm

348 incurred losses between 5 and 66\% in 2018 (measured in percent of prepared bags of substrate

349 that did not go on to yield mushrooms). According to farmers, the minimum loss rate has been

350 achieved simply through rigorously following the sanitation protocol, including washing hands,

351 wearing lab coats and shoe covers, and keeping doors of the cultivation rooms closed. Average

352 loss rates were used in this LCA study, but since minimum loss rates are achievable with no

353 other changes in production, a scenario with optimal production was modeled using the

354 minimum loss rate recorded in 2018 (5\%).

\section{3 . Results}

356 The impacts of production of 1 kilogram of oyster mushrooms are presented in Table 2 . The

357 percent contribution of each life cycle stage to the overall life-cycle impacts is shown in Figure

358 2Erreur ! Source du renvoi introuvable.. No single life cycle stage dominated all impact

359 categories, but the substrate transformation and cultivation stages were both dominating 
contributors to several impact categories. The packaging and delivery stage was extremely important in land occupation, and the substrate materials stage generally had modest contributions of $8-27 \%$ but was not the major factor in any impact category.

363 Substrate transformation was the major contributor to CC impacts throughout the life cycle, 364 accounting for $44 \%$ of the greenhouse gas (GHG) emissions. In fact, a single process within this 365 stage, gas consumption for pasteurization in the autoclave, accounted for $43 \%$ of the CC 366 impacts for the entire life cycle. Substrate materials contributed $24 \%$ of the CC impacts over the 367 life cycle, mostly from the frequent delivery of materials. The cultivation stage, which was 368 comprised nearly exclusively of electricity inputs, accounted for $13 \%$ of the CC impacts, largely 369 from air temperature regulation. Packaging and delivery of the final product had a modest 370 contribution of $13 \%$ to CC impacts, with transport contributing about twice as much as the 371 packaging materials. Finally, carbon sequestration of SMS accounted for $6 \%$ of CC impacts.

372 Contributions to CC were broken down by process type in addition to life cycle stage. The 373 process categories considered were gas, electricity, transport, and materials. Transport included 374 weekly delivery of SCGs and mycelium, infrequent delivery of wood chips and $\mathrm{CaCO}_{3}$, and daily 375 delivery of mushrooms to the market. Material included impacts from producing the materials 376 themselves. Electricity and gas included their use on the farm, and the background processes 377 embedded in the database. The categories of gas, electricity, transport, and material 378 contributed 43\%, 14\%, 31\%, and 12\%, respectively (Figure 3). Transport from short supply 379 chains, which here were the SCGs and mushroom delivery, contribute $16 \%$ of the CC impacts (7 380 and $9 \%$ respectively). 
381 Carbon sequestration from SMS amounted to $0.19 \mathrm{~kg} \mathrm{CO} 2 \mathrm{eq} / \mathrm{kg}$ mushroom stored in the soil.

382 This amount was subtracted from the CC impact to give a net CC impact of $2.99 \mathrm{~kg} \mathrm{CO} / \mathrm{kg}$

383 mushroom, which was a $6 \%$ abatement. This reduction was rather small because most of the

384 benefits from carbon sequestration were actually allocated to the SMS co-product instead of

385 the mushrooms.

386 The cultivation stage, with its many electricity inputs, drove the ED with a $60 \%$ share.

387 Specifically, air temperature regulation and LED lighting were the largest contributors, with $38 \%$

388 and $13 \%$ of the ED over the entire life cycle, respectively. Although gas powered pasteurization

389 drove the CC impacts, which are often closely linked with ED, it only contributed $15 \%$ of the ED

390 impacts. This is because the electricity grid in France is largely composed of nuclear energy

391 rather than fossil fuels, so the processes using electricity rather than gas benefitted from low CC

392 impacts (International Energy Agency, 2017).

393 The direct land occupation of the farm site was small compared to the demands on land in the

394 background system, contributing $12 \%$ and $88 \%$, respectively. LU impacts were mostly from

395 wood for wooden crates, used as packaging, which contributed $58 \%$ of impacts. The remaining

396 LU impacts came mostly from agricultural production of rye, which contributed $22 \%$ of impacts

397 and was used in the production of mycelium for substrate materials.

398 WD was driven by a variety of different processes with water use occurring in the both

399 foreground and background systems. Most of the contributions came from the cultivation stage

400 (69\%), due to water demands from cleaning rooms (where the production rooms are

401 periodically washed down with a hose), humidification of cultivation rooms, and air 
402 temperature regulation. The water used for the room cleaning and humidification was tap

403 water used on-site at the farm, while for air temperature regulation the water used was from

404 electricity production in the background system. Most of the water use can be placed in one of

4053 categories: electricity, on-site tap water, or embodied water in the wooden crates (Table 3).

406 Impacts to FE were driven by the cultivation stage, mostly from electricity production, with $41 \%$

407 of the total impacts. Other sources of FE came from the transport in the substrate materials and

408 packaging and delivery stages, accounting for $17 \%$ and $14 \%$ of total FE impacts, respectively.

$409 \quad$ 3.1. Sensitivity analyses

410 If the same production system were located in and used the electricity mixes of neighboring

411 countries Germany, Italy, or Spain, the CC impacts (with carbon sequestration) would increase

412 to $7.65,6.00$, and $5.29 \mathrm{~kg} \mathrm{CO} 2 \mathrm{eq} / \mathrm{kg}$ mushroom, respectively. However, the ED would decrease

413 by $16-31 \%$, likely due to differing efficiencies of electricity production.

414 In the second sensitivity analysis, results showed differences of 5-22\% in impacts between the

415 two allocation methods, showing mixed responses across impact categories (Figure 4). WD was

416 the most sensitive with a $22 \%$ difference between allocation methods, whereas CC was the least

417 affected. One method did not have consistently higher or lower impacts than the other, and the 418 choice of allocation system had mixed effects overall.

\section{3.2. Alternative scenarios}

420 In the first alternative scenario we modeled a more efficient transport scheme where deliveries

421 were done less frequently but a larger volume was shipped each time. Despite the farm's focus

422 on local material sourcing and delivery of mushrooms, there was a substantial impact from 
423 short supply chain transport to the total CC impacts (16\%). If the weekly deliveries of SCGs and

424 mycelium were cut in half to delivery every 2 weeks, the CC impact (with carbon sequestration)

425 would decrease by $10 \%$ to $2.70 \mathrm{~kg} \mathrm{CO}_{2}$ eq. Further reductions of $5 \%$ could be made by

426 harvesting and delivering mushrooms every two days, resulting in $2.55 \mathrm{~kg} \mathrm{CO}_{2}$ eq. emitted per

$427 \mathrm{~kg}$ of mushrooms. These adjustments to the supply chain would result in a net reduction of GHG

428 emissions of $15 \%$.

429 Next we modeled a scenario where straw was used instead of SCGs, because it is a more typical

430 substrate material for oyster mushroom production. Production with the straw-based substrate

431 had much larger impacts than a SCG-based substrate for FE (33\% larger) and LU (784\% larger),

432 and slightly larger impacts for WD (6\%). The cultivation of straw accounted for a large majority

433 of these impacts, which was expected because they are all closely tied to agricultural

434 production, and straw is a by-product of grain production. CC and ED impacts were lower for the

435 straw-based substrate by $5 \%$ and 3\%, respectively. CC and ED impacts are not largely changed

436 by this substitution of straw because, like SCGs, straw is a byproduct of another system with

437 little value. Therefore, straw was allocated a minor share of these impacts (7-10\%). In both

438 scenarios the CC and ED impacts of materials themselves are small. The delivery logistics of

439 those materials emerge as the more important factor driving impacts, where the straw-based

440 substrate scenario has less frequent deliveries than the baseline SCG scenario.

441 Finally we evaluated the impacts of a scenario with realistically increased mushroom yields,

442 using the minimum loss rate recorded on the farm. This linearly reduced all environmental

443 impacts by $43-46 \%$, except for LU, which decreased by $19 \%$. LU responded differently because it

444 is largely affected by wooden crate use for packaging, and the amount of packaging was one of 
445 the few inputs that increased with increased in production. For example, the resulting CC

446 impacts with and without carbon sequestration dropped to 1.71 and $1.81 \mathrm{~kg} \mathrm{CO} 2$ eq.

447 respectively.

\section{4. Discussion}

\subsection{Effects of circular economy and short supply chains}

450 The mushroom farm had low CC impacts from the materials used, accounting for only $12 \%$ of

451 the total impact. This suggests that the circular economy model, which was prioritized in the

452 farm design by focusing on upcycling opportunities, was effective at minimizing its impacts.

453 Furthermore, we hypothesized that upcycling of SCGs represented a "more circular" production

454 system than more commonly-used agricultural byproducts such as straw. A comparison to

455 oyster mushroom cultivation with straw showed this was true for some impacts (WD, LU and

$456 \mathrm{FE}$ ), but other impacts (ED and CC) were not largely affected, because reusing straw (a

457 byproduct) is also a circular system itself. However, the farm-level scope of this LCA did not

458 allow us to model other benefits of using SCGs that would likely be reflected in the CC and ED

459 categories. In particular, the diversion of SCGs away from incineration can generally be

460 considered a net benefit despite a possible energy-generation from incineration (Beylot and

461 Villeneuve, 2013), whereas straw would not be incinerated because it has many applications

462 and its own market. Specifically, municipal waste collection and treatment of the SCGs used per

463 kilogram of mushroom at the farm, using the average French waste treatment mix, would incur

464 an emission of $1.98 \mathrm{~kg} \mathrm{CO}$ eq / $\mathrm{kg}$ mushroom, which is substantial compared to the impacts of

465 using the same amount of SCGs for mushroom production (2.99 $\mathrm{kg} \mathrm{CO} 2 \mathrm{eq} / \mathrm{kg}$ mushroom). 
Additionally, the use of urban-generated waste (SCGs) within urban and peri-urban agriculture

467 can create new links between local businesses and promote innovation. Using this scope of

468 study, it is difficult to evaluate the full advantages of upcycling SCGs.

469 The circular approach of using SMS as a soil amendment is reflected in the results, in that there

470 were no burdens from waste management and there were some benefits from carbon

471 sequestration. However the actual impact of avoided waste management of SMS, and the

472 corresponding credits to the farm, are not explicitly shown in our results, according to our

473 modeling decisions. Furthermore, the farm's intentional placement in a peri-urban area nearby

474 the farms that use SMS allows for reduced transport distances, which were not attributed to the

475 mushroom farm given the system boundaries we set.

476 Regarding the short supply chain aspect of the farm, it appears that the environmental benefits

477 of a reduced distance for transport is offset by frequent trips with small volumes. Average food

478 supply chains have transport processes contributing moderately to CC impacts, with 6-11\%

479 through the entire life cycle and specifically $4 \%$ from delivery to the final distribution point

480 (Robinson et al., 2018; Weber and Matthews, 2008). Transport at the mushroom farm incurred

481 significant CC impacts, with a $31 \%$ share overall, in which $10 \%$ came from the final delivery of

482 the product. Although an emphasis is often placed on the delivery of the final product, impacts

483 from transportation of input materials outweighed product deliveries, as has been found in

484 other studies (Martin and Molin, 2019). These contribution calculations only consider the

485 transport in the foreground system, and not transport processes embedded in the database

486 representing the background system, so the actual contribution of transport could be even

487 larger. Our findings support claims that proximity alone is not a sufficient indicator of 
environmental sustainability, and individual attributes and practices of the system can play a more important role (Edwards-Jones et al., 2008; Kiss et al., 2019; Mundler and Rumpus, 2012).

Overall, processes related to materials from circular economy and transport from short supply

491 chains are not the major sources of impacts across the life cycle. Rather, on-site energy

492 consumption from gas and electricity are extremely impactful. Efforts to improve energy

493 efficiency, or reduce energy use altogether, would likely have more significant benefits to

494 environmental sustainability than making changes to the substrate recipe and changing

495 materials, as the farm currently is focusing on. The most impactful and easiest to implement

496 measures for reducing impacts actually do not require changes in material, transportation or

497 implementing circular economy principles, but adjustments to farmers' behavior to avoid pests

498 and diseases so as to increase the mushroom yield.

\subsection{Energy source and climate change}

500 ED at the mushroom farm was relatively high, and was comparable with the ED of greens and 501 herbs in an indoor high-tech hydroponic system (Pennisi et al., 2019). They calculated ED per 502 kilogram in 20 different production systems, and found a range of 53-227 MJ/kg, with an 503 average of $145 \mathrm{MJ} / \mathrm{kg}$, compared to $143 \mathrm{MJ} / \mathrm{kg}$ of mushroom found here. Despite this intense ED 504 here, the CC impacts were not proportionally large, compared to other mushroom LCA studies.

505 This is due to the particular electricity grid of France that was used in this study, which is 506 composed of 78\% nuclear energy (Ecoinvent, 2018; International Energy Agency, 2017). This

507 allowed for relatively low GHG emissions at the expense of ionizing radiation and other impacts, 508 which were not discussed but are presented in Table A1 in the Appendix. In the case of indoor 
509 farming, where large amounts of energy are used, the electricity grid can have a large influence

510 on the resulting CC impacts. In another mushroom farming LCA, Robinson et al. (2018) found

511 important variations in the CC impacts when looking at regions of the USA with different energy

512 grids using more or less coal or renewable energy. Considering LCAs of indoor hydroponic

513 vegetable farming, which similarly use large amounts of energy, Martin and Molin (2019) found

514 approximately 33\% increases in CC impacts when using a Nordic electricity mix rather than a

515 Swedish mix in a farm growing basil. In an indoor hydroponic farm growing leafy greens, Romeo

516 et al. (2018) found a decrease in CC impacts of $60 \%$ when modeling the difference between the

517 French electricity grid and a wind powered electricity source. This variability highlights the

518 importance of reporting ED in LCAs because this metric is not sensitive to geographic variation

519 in electricity grids.

\section{$520 \quad$ 4.3. Comparison to other mushroom LCAs}

521 It is difficult to directly compare our results to other mushroom LCA studies because most have

522 focused on the common button mushroom (Agaricus bisporus), which has different cultivation

523 practices and substrate materials from the oyster mushroom studied here. Additionally,

524 differences in regional and farm-specific practices, background systems, and modelling choices

525 can always lead to differences in results, with unknown importance. Nonetheless, it is useful to

526 cautiously present other mushroom LCA results to position our work.

527 The only other published oyster mushroom LCA comes from production in Thailand at farms of 528 multiple sizes (Ueawiwatsakul et al., 2014). Our case study is comparable to the small farm size 529 they defined $(<20,000$ kilograms mushrooms produced per year), and major differences include 
530 the substrate, which was composed largely of sawdust in Thailand, and the generation of steam

531 from firewood combustion. Despite these differences, similar CC impacts were calculated,

532 amounting to $3.01 \mathrm{~kg} \mathrm{CO}$ eq. / $\mathrm{kg}$ mushroom (Figure 5 ). However, medium sized farms had

533 larger impacts, of $5.0 \mathrm{~kg} \mathrm{CO}$ eq. $/ \mathrm{kg}$ mushroom. They also found large burdens from sterilization

534 of substrate and transport of substrate materials, although due to unique local/regional

535 constraints.

536 More studies are available for the production of the button mushroom (Agaricus bisporus)

537 because it is a more common mushroom. Gunady et al. (2012) assessed button mushroom

538 cultivation in Western Australia and calculated GHG emissions close to ours (at $2.75 \mathrm{~kg} \mathrm{CO} 2$

539 eq. $/ \mathrm{kg}$ mushroom), and found that the largest contribution was from transportation of raw

540 materials, especially the regular transportation of compost from $46 \mathrm{~km}$ away. To reduce this

541 impact, they suggested using energy efficient and low GHG fuels, increasing the load factor of

542 trucks to $100 \%$, and avoiding an empty return. They did not mention reducing the frequency of

543 material delivery. In Leiva et al.'s (2015a) LCA of button mushroom production in Spain, CC

544 impacts amounted to $4.42 \mathrm{~kg} \mathrm{CO} 2$ eq./ $/ \mathrm{kg}$ mushroom, largely due to energy consumption during

545 the growing process and distribution. An LCA of button mushroom production in the USA by

546 Robinson et al. (2018) showed smaller CC impacts between $2.13-2.95 \mathrm{~kg} \mathrm{CO} 2$ eq./kg mushroom.

547 Electricity use, fuel consumption and methane from compost emissions made up the majority of

548 the impacts. Total transport emissions only contributed 6-9\% of CC impacts, which further

549 contrasts with the high contribution of transport in our study (31\%) despite the peri-urban farm

550 using mostly locally sourced materials. 
551 Oyster and button mushrooms have different nutritional and energy contents, with 33 and 22

$552 \mathrm{kcal} /$ kilogram, respectively (U.S. Department of Agriculture and Agricultural Research Service,

553 2019). Comparing CC results based on energy content, rather than mass, shows oyster

554 mushrooms performing slightly better than button mushrooms (Figure 5). This concurrence

555 evidences the robustness of our comparison, and supports the conclusion that CC impacts were

556 within the range of other mushroom farms.

\subsection{Considerations for LCA modeling}

558 The boundary of the system excluded delivery to the final consumer, which was a limitation 559 because this can be an impactful stage (Mundler and Rumpus, 2012). Additionally, we used data

560 from the farm for a 2 month period of production, which risks being unrepresentative of the 561 annual production. However we verified that, although this was one of the most productive 562 periods for the farm during 2018, a proportionally large amount of materials and energy were

563 used as well. Finally, any study on sustainability is limited when it only considers one aspect, 564 where here we focused on environmental sustainability. An inclusion of economic and social 565 aspects would be holistic and ideal, but was outside the scope of this study.

566 It should be noted that a system modeling choice likely has a large impact here: the decision to 567 treat SCGs, a recycled input, using Ekvall and Tillman's (1997) simple cut off method instead of 568 system expansion and avoided burdens. This choice is necessary because SCGs are a recycled 569 product from the system that created both a beverage in the product's first life cycle, and a 570 mushroom cultivation substrate in its second life cycle. The ISO recommendations for allocation 571 are difficult to apply here (with the following hierarchy: subdivision, system expansion, 
572 physical/causal relationships, economic) because the relationship between this primary product

573 and the recycled product is unclear (ISO, 2006). In this example, if we were to use the system

574 expansion method to include the avoided burden of waste treatment of SCGs, then the impacts

575 of the SCG life cycle must also be attributed. In other words, in order to assign positive impacts

576 (avoided burdens) to SCGs, they must also be assigned their fair share of negative impacts as

577 well. To assign those impacts, an allocation must be done between the coffee grounds for

578 making coffee (product of first life cycle) and the recycled SCGs (product second life cycle).

579 There is no satisfactory way to allocate between these two product life cycles and assign

580 negative impacts, so positive impacts from avoided burdens cannot fairly be assigned, and the

581 cut-off method emerges as the most reasonable solution.

\subsection{LCA for circular economy}

583 Several benefits of a circular approach could not be explicitly quantified and highlighted in this 584 study due to our consideration of just the mushroom farm, as opposed to, for example, the 585 cafés producing SCGs and the mushroom farm and the farms applying SMS. One such benefit 586 was the avoided waste treatment of SCGs, which was not included. Additionally, in order to 587 reduce environmental impacts, the farm was established in a peri-urban area to balance 588 distance between urban consumers of fresh mushrooms and peri-urban farmers using SMS.

589 Because the SMS exits the system boundary once the farmers pick it up, this reduced distance 590 was not reflected in the results, although it is a consequence of a choice by the farm. In another 591 LCA of a circular food production system, Strazza et al. (2015) assessed the production of fish 592 feed from food waste on a cruise ship. Taking a similar limited, sub-system only approach, they 593 also did not assign credits for the avoided burden of food waste management when it was 
594 upcycled, but acknowledge that the disposal of this organic waste in a landfill would be a

595 significant driver of environmental impacts. Our results suggest that the application of LCA in

596 agricultural circular economy systems is restrictive when applied to an isolated subsystem, such

597 as one farm. Indeed, circular economies are composed of a complex network of actors, and

598 studying only one actor does not capture the beneficial exchanges that may be placed outside

599 of their system boundary and inside the system of another (Zhang et al., 2013). An approach

600 that includes the activities of several actors in a circular economy could be better suited to

601 capture the total advantages of circularity in complex systems (Fan et al., 2018; Oldfield et al.,

602 2017). Therefore, we recommend that when aiming to study circular economy aspects with LCA,

603 a network-level scope should be taken.

604 4.6. Responses from the mushroom farm

605 We partnered with a functioning commercial farm and used data from real cultivation practices,

606 rather than a research farm, pilot project, or relying heavily on data from the literature. In

607 addition to the scientific value of this work, we hoped to provide meaningful insight and

608 decision support for the farmers, who were concerned about the environmental sustainability

609 of their practices and looking for feasible paths to improve. An academic-oriented LCA may not

610 naturally generate results that are most interesting to the farmers. For example, because we

611 were interested in the short supply chain aspect of the farm, we modeled an alternative

612 scenario with reduced delivery frequency that reduces CC impacts by $15 \%$. The farmers quickly

613 rejected this strategy because their oyster mushrooms must be delivered daily, as they are the

614 only provider of this specialty product to the market and are constrained by customer demand.

615 SCGs and mycelium could not be delivered in larger quantities because they would not have the 
616 space to store them, and because the risk of pathogen contamination would increase. The most

617 feasible improvement, according to the farmers, is the increased yield scenario, where simple

618 sanitary actions by the workers could reduce contamination, attain their highest production

619 rates from 2018, and reduce all impacts by $43-46 \%$. Although they were already aware that they

620 should address the issue of contamination, they said that these results have strongly motivated

621 them and their workers to make it a top priority. One unexpected result was the importance of

622 gas pasteurization to $\mathrm{CC}$, and in response the farmers are exploring ways to mitigate it by

623 contacting the manufacturer of the pasteurization machine to adjust settings, insulating the

624 machine, and installing an electricity-powered machine in a new farm under development. Our

625 experience highlights the importance of partnering with functioning, commercial enterprises

626 and maintaining open dialogues with farmers to consider not only the academic but also the

627 practical outcomes of this type of research.

628 5. Conclusion

629 We conducted an LCA of the production of $1 \mathrm{~kg}$ of oyster mushrooms at a circular, urban farm

630 next to Paris. Our goal of quantifying the environmental impacts and identifying the most

631 impactful parts of production yielded valuable results and insight. On-farm energy use emerged

632 as the most important activity for most impact categories, followed by transportation

633 throughout the life cycle. The use of materials had low impacts in most impact categories due to

634 the emphasis put on upcycling in the farm's production design. However, our second goal of

635 investigating the circular economy advantages and disadvantages of the system was met with

636 limited success. This was because our decision to study only the farm as an isolated component 
637 of a network of actors excluded several processes that may have large environmental impacts, 638 positive or negative. The tradeoff here was that we were able to study activities at the urban 639 mushroom farm in greater detail, which was valuable because, to the best of our knowledge, an 640 LCA has not been done before on this novel type of food production.

641 Mushroom farming is indeed a relevant application of circular economy and provides many 642 opportunities for closing material and energy loops. The largest improvements in environmental 643 performance could come from an increased commitment to sanitation practices, which would 644 minimize mushroom losses and maximize yield. The circular approaches adopted at the 645 mushroom farm contributed to environmental sustainability, but on-farm energy use was more 646 important in many impact categories. Compared to more typical mushroom farms studied in 647 other LCAs, this farm had similar CC impacts. However, there is potential for considerably 648 reduced impacts if high mushroom yields can be maintained. Comparing different input 649 materials showed large environmental advantages of using SCGs instead of straw. In some cases 650 of circular food production systems, the most significant enhancements to environmental 651 sustainability may come from efficiency improvements within the system rather than further 652 integrating circular principles. 


\section{Acknowledgements}

654 The authors gratefully acknowledge financial support of lab recherche environnement VINCI ParisTech.

655 Figures and Tables

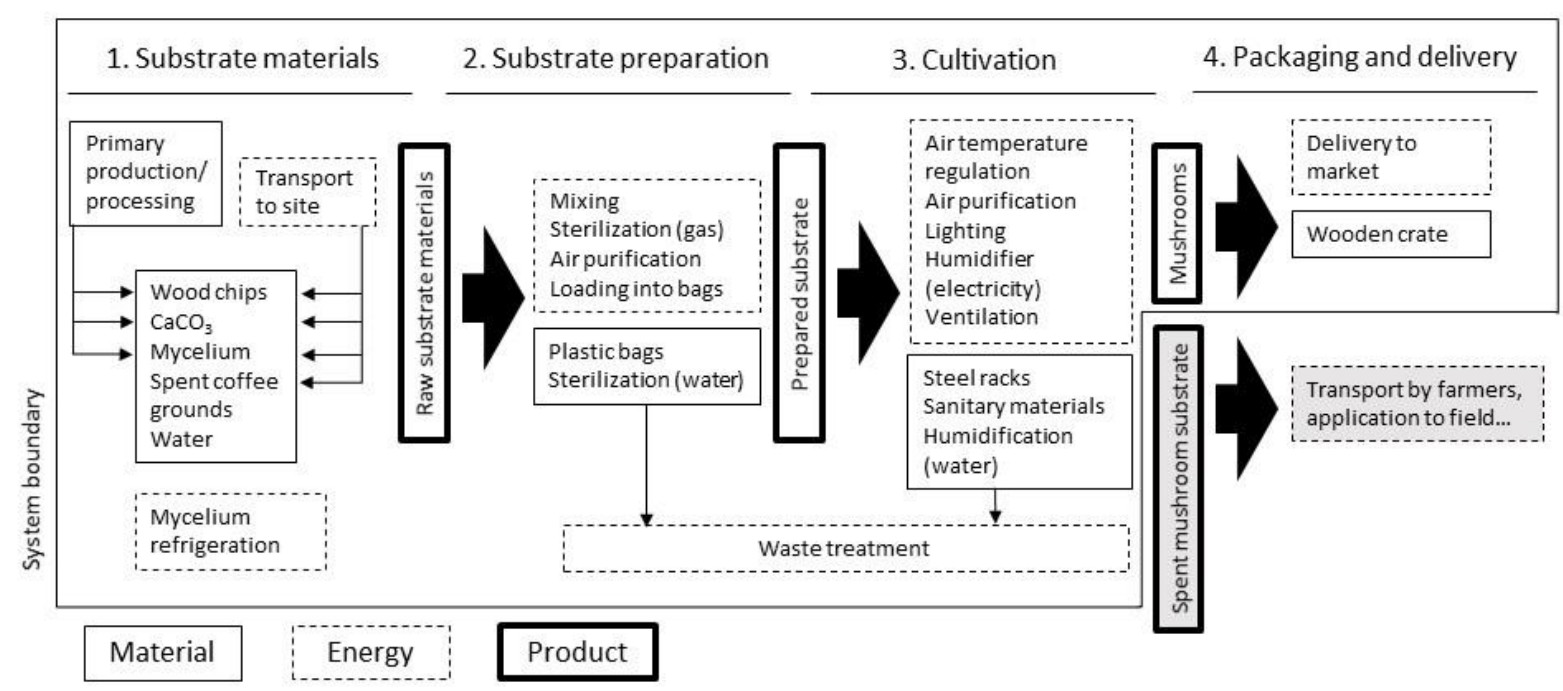

657 Figure 1: The process diagram of production at the mushroom farm shows what was included in the 658 system boundary, and how life cycle stages were delineated. 


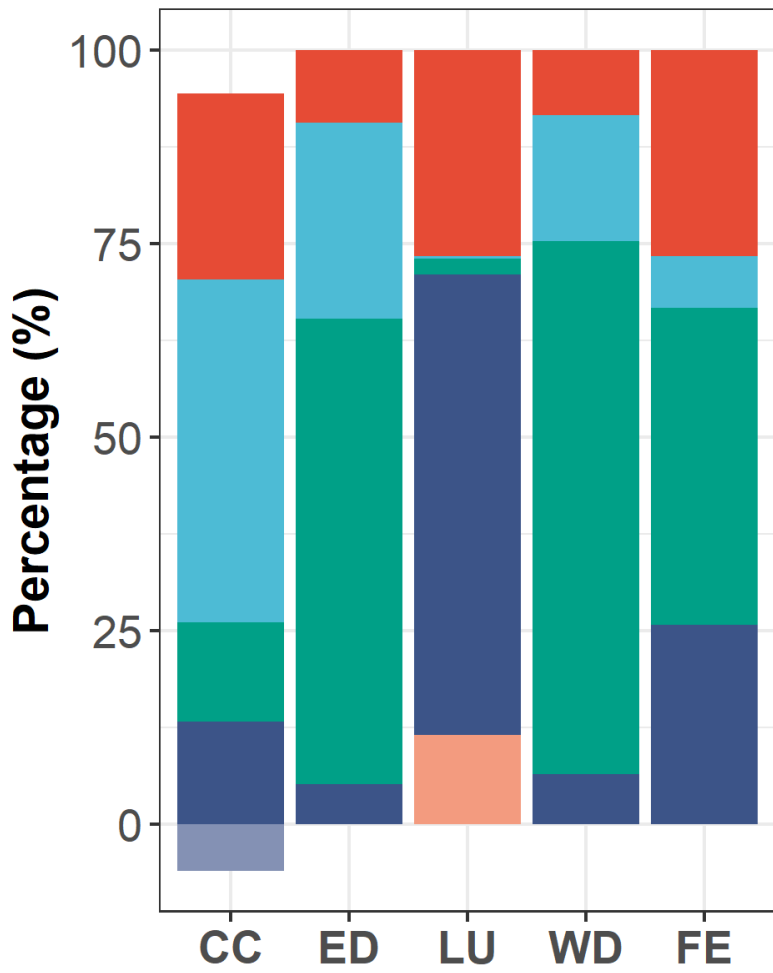

\section{Life cycle stage}

Substrate Materials

Substrate Transformation

Cultivation

Packaging and Delivery

Direct land use

Carbon sequestration SMS

660 Figure 2 The contribution of each life cycle stage to each impact category is shown. The impact

661 categories are climate change (CC), non-renewable energy demand (ED), land use (LU), water depletion 662 (WD), and freshwater eutrophication (FE).

663 


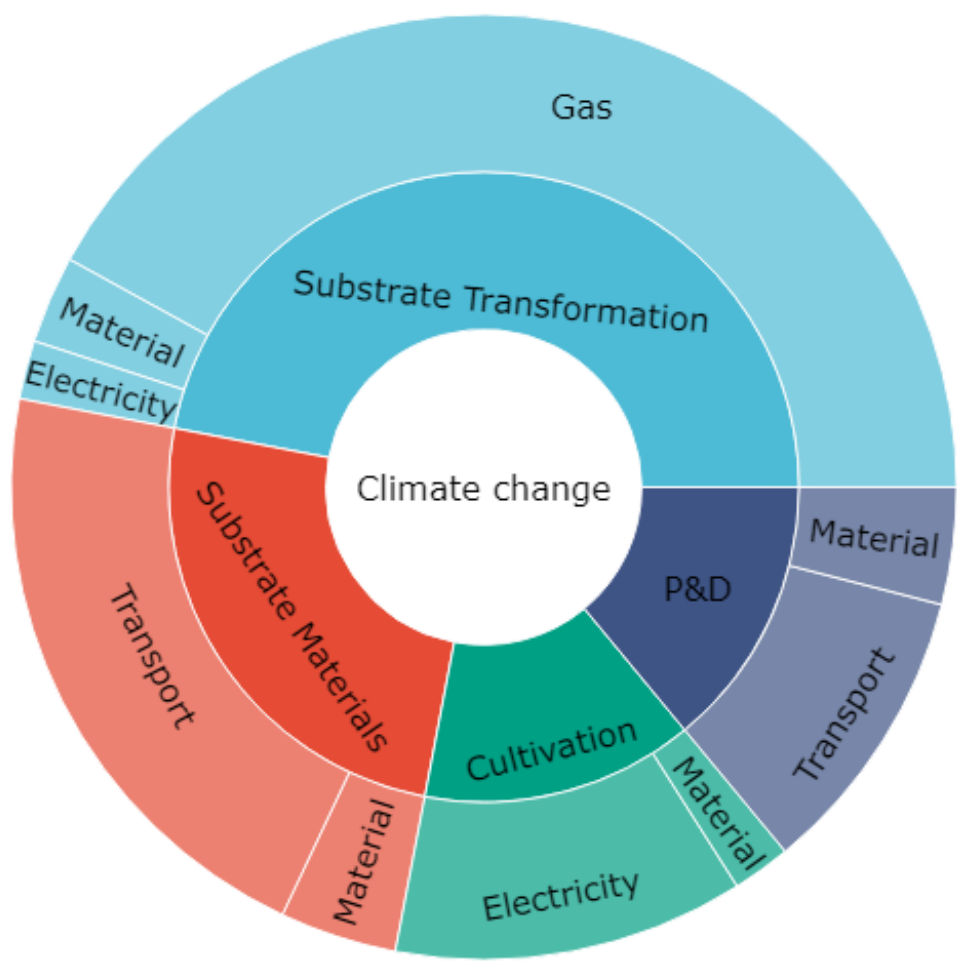

664

665 Figure 3 The proportion of climate change impacts are broken down by life cycle stage in the inner circle, 666 and by process type in the outer circle. The abbreviation P\&D stands for "Packaging and Delivery". 


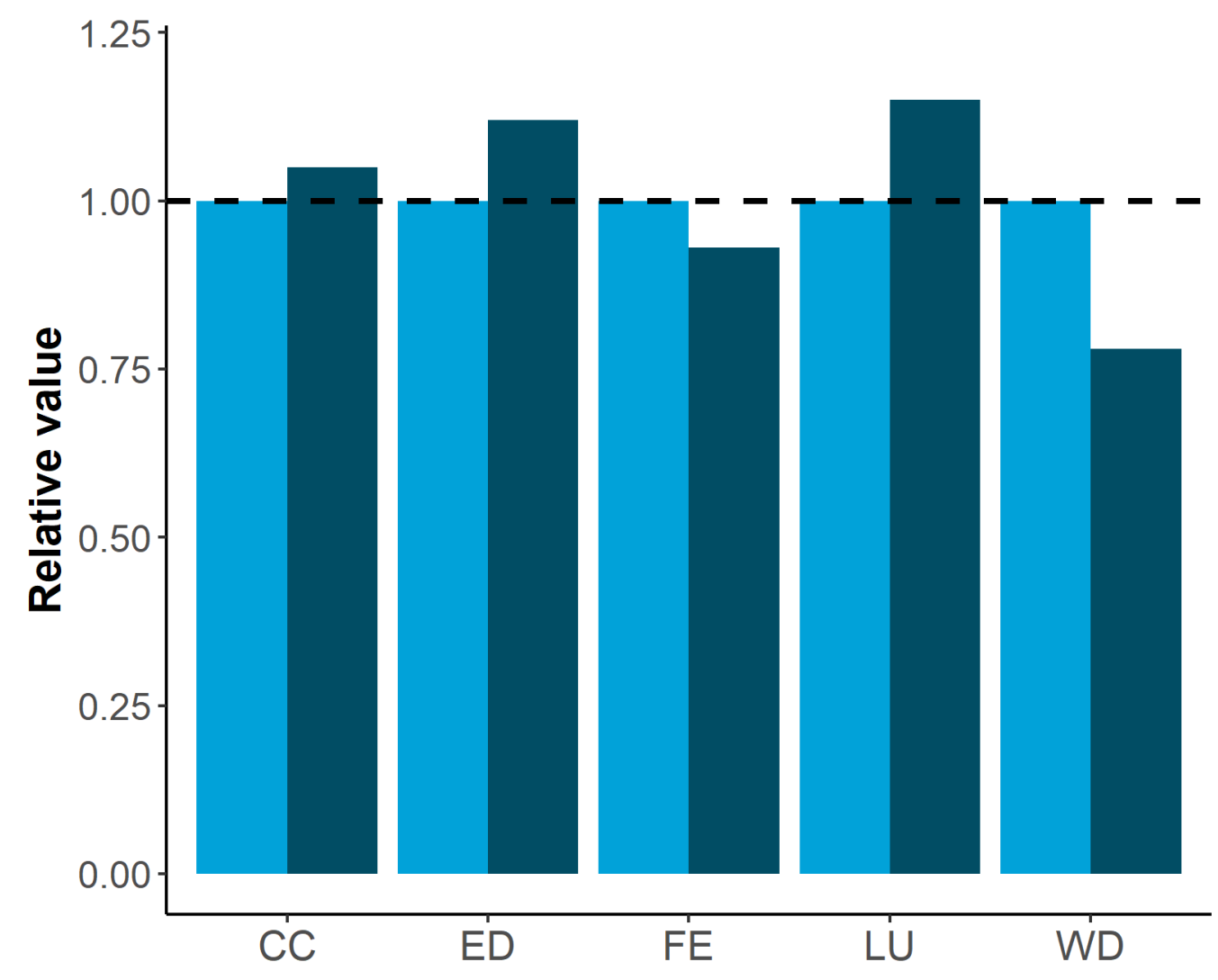

\section{Method Economic allocation System expansion}

668 Figure 4 Impacts are compared between use of economic allocation (the main method used in this study)

669 and an alternative method, system expansion, to treat the co-product spent mushroom substrate. The

670 impact categories are cliamte change (CC), non-renewable energy demand (ED), land use (LU), water

671 depletion (WD), and freshwater eutrophication (FE). For some impact categories, there is a large

672 difference between allocation methods, and for some there is hardly any difference. 


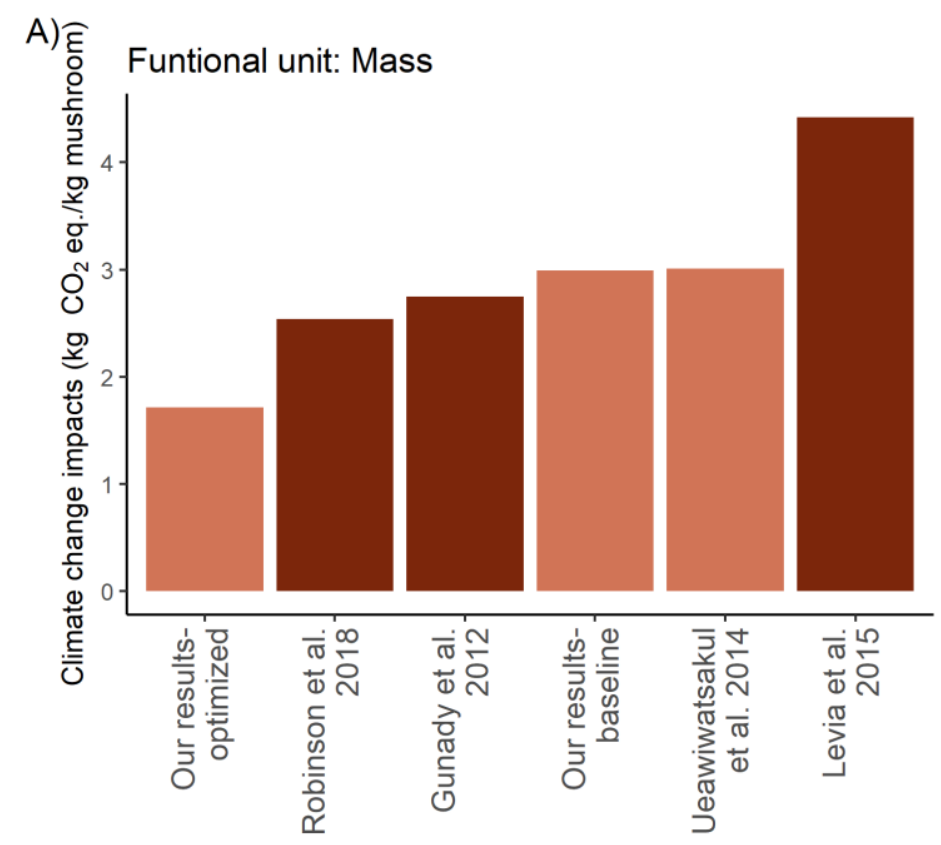

B)

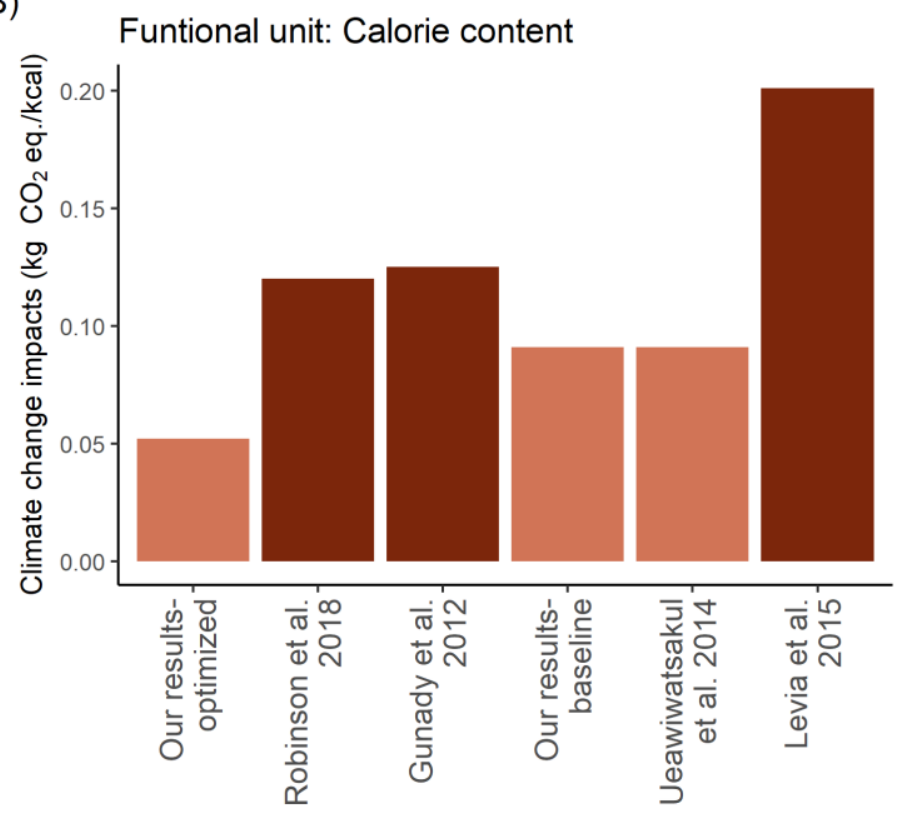

Type of mushroom

Button (Agaricus)

Oyster (Pleurotus)

674

675 Figure 5 Comparing the climate change impacts calculated in this study to the results from other

676 mushroom LCAs showed that the baseline scenario for the circular, urban farm performed similarly to

677 other mushroom farms. However, under the optimized yield scenario, impacts were much smaller at the

678 circular urban farm. When using calorie content as a functional unit instead of mass, oyster mushrooms

679 perform slightly better than button mushrooms. 


\begin{tabular}{|c|c|c|c|c|}
\hline Life cycle stage & Input & Material & $\begin{array}{l}\text { Value per } \\
\text { FU }\end{array}$ & Unit \\
\hline \multirow{9}{*}{$\begin{array}{l}\text { Substrate } \\
\text { materials }\end{array}$} & Coffee grounds & Transport, 3.7-7.5 ton lorry (EURO 5) & 435.2 & kgkm \\
\hline & \multirow{2}{*}{ Wooden chips } & Wood chips, as a byproduct & 1.500 & $\mathrm{~kg}$ \\
\hline & & Transport, 3.7-7.5 ton lorry (EURO 5) & 145.2 & kgkm \\
\hline & \multirow{2}{*}{$\mathrm{CaCO}_{3}$} & Lime & 0.063 & $\mathrm{~kg}$ \\
\hline & & Transport, 3.7-7.5 ton lorry (EURO 5) & 0.535 & kgkm \\
\hline & \multirow{3}{*}{ Mycelium } & Mycelium inoculated rye seeds & 0.358 & $\mathrm{~kg}$ \\
\hline & & Transport, 3.7-7.5 ton lorry (EURO 5) & 708.8 & kgkm \\
\hline & & $\begin{array}{l}\text { Electricity (for refrigeration), French } \\
\text { grid }\end{array}$ & 0.012 & $\mathrm{kWh}$ \\
\hline & Water & Tap water & 1.137 & $\mathrm{~kg}$ \\
\hline \multirow{8}{*}{$\begin{array}{l}\text { Substrate } \\
\text { transformation }\end{array}$} & Air purification & Electricity, French grid & 0.132 & kWh \\
\hline & Conveyor belt & Electricity, French grid & 0.079 & kWh \\
\hline & Substrate mixing & Electricity, French grid & 0.552 & $\mathrm{kWh}$ \\
\hline & Substrate cooling & Electricity, French grid & 0.110 & $\mathrm{kWh}$ \\
\hline & Sterilization: Gas & Sour gas, global average & 5.534 & $\mathrm{kWh}$ \\
\hline & $\begin{array}{l}\text { Sterilization: } \\
\text { Water }\end{array}$ & Tap water & 5.765 & $\mathrm{~kg}$ \\
\hline & Plastic bags & Polyethylene, low density & 0.032 & $\mathrm{~kg}$ \\
\hline & Air purification & Electricity, French grid & 0.188 & kWh \\
\hline \multirow{7}{*}{ Cultivation } & $\begin{array}{l}\text { Air temperature } \\
\text { regulation }\end{array}$ & Electricity, French grid & 4.403 & kWh \\
\hline & Humidifier & Electricity, French grid & 0.117 & $\mathrm{kWh}$ \\
\hline & LED lighting & Electricity, French grid & 1.539 & kWh \\
\hline & Ventilation & Electricity, French grid & 0.478 & $\mathrm{kWh}$ \\
\hline & Water & Tap water & 19.461 & $\mathrm{~kg}$ \\
\hline & Steel racks & Steel, low-alloyed & 0.0082 & $\mathrm{~kg}$ \\
\hline & & Polypropylene & 0.0007 & $\mathrm{~kg}$ \\
\hline
\end{tabular}




\begin{tabular}{|l|l|l|l|l|}
\hline \multirow{2}{*}{$\begin{array}{l}\text { Sanitary } \\
\text { materials }\end{array}$} & Polyethylene, low density & 0.0012 & $\mathrm{~kg}$ \\
\cline { 3 - 5 } & Polyethylene, high density & 0.0016 & $\mathrm{~kg}$ \\
\cline { 3 - 5 } & Synthetic rubber & 0.0019 & $\mathrm{~kg}$ \\
\hline \multirow{3}{*}{$\begin{array}{l}\text { Packaging and } \\
\text { delivery }\end{array}$} & Wood crates & Plywood, for indoor use & 0.186 & $\mathrm{~kg}$ \\
\cline { 2 - 5 } & Transport, 3.7-7.5 ton lorry (EURO 5) & 61.801 & $\mathrm{kgkm}$ \\
\cline { 2 - 5 } & Delivery & $\begin{array}{l}\text { Transport, passenger car, large size, } \\
\text { diesel (EURO 5) }\end{array}$ & 0.772 & $\mathrm{~km}$ \\
\hline
\end{tabular}

680

Table 1 The full life cycle inventory for the production of $1 \mathrm{~kg}$ of mushrooms is shown, separated by life cycle stages. The economic allocation between the farm's two products- mushrooms and spent mushroom substrate- has already been applied, giving the mushroom system $84.8 \%$ of all material and energy inputs.

681

682

\begin{tabular}{|l|l|l|}
\hline Impact category & Value & Unit \\
\hline Climate change (with C seq.) & 2.99 & $\mathrm{~kg} \mathrm{CO}_{2}$ eq. \\
\hline Climate change (without C seq.) & 3.18 & $\mathrm{~kg} \mathrm{CO} 2$ eq. \\
\hline Non-renewable energy demand & 143 & $\mathrm{MJ}$ \\
\hline Land use & 169 & $\mathrm{Pt}$. \\
\hline Water scarcity & 2.42 & $\mathrm{~m}^{3}$ depriv. \\
\hline Freshwater eutrophication & $4.65 \mathrm{E}-04$ & $\mathrm{~kg} \mathrm{P}$ eq. \\
\hline
\end{tabular}

683 Table 2 Life cycle impact assessment results are shown at the level of characterization. Climate change 684 impacts are presented with and without the carbon sequestration contribution from spent mushroom 685 substrate.

686 


\begin{tabular}{|c|c|c|c|c|c|}
\hline & $\begin{array}{l}\text { Substrate } \\
\text { Materials }\end{array}$ & $\begin{array}{l}\text { Substrate } \\
\text { Transformation }\end{array}$ & Cultivation & $\begin{array}{l}\text { Packaging } \\
\text { and } \\
\text { delivery }\end{array}$ & Sum \\
\hline $\begin{array}{l}\text { Industrial water } \\
\text { (electricity) }\end{array}$ & $1 \%$ & $5 \%$ & $34 \%$ & $0 \%$ & $40 \%$ \\
\hline Tap water (on site) & $3 \%$ & $10 \%$ & $35 \%$ & $0 \%$ & $48 \%$ \\
\hline Wooden crates & $0 \%$ & $0 \%$ & $0 \%$ & $5 \%$ & $5 \%$ \\
\hline Other & $4 \%$ & $1 \%$ & $0 \%$ & $2 \%$ & $7 \%$ \\
\hline Sum & $8 \%$ & $16 \%$ & $69 \%$ & $7 \%$ & $100 \%$ \\
\hline
\end{tabular}

Table 3 There was important water scarcity impacts in the foreground system from tap water use on the farm, and in the background system from electricity generation. Wooden crates, used for packaging, had particularly high embodied water scarcity impacts.

\section{Bibliography}

Ansorge, L., Beránková, T., 2017. LCA Water Footprint AWARE Characterization Factor Based on Local Specific Conditions. Eur. J. Sustain. Dev. 6, 13-20. https://doi.org/10.14207/ejsd.2017.v6n4p13

Beck, T., Bos, U., Wittstock, B., Baitz, M., Fischer, M., Sedlbauer, K., 2010. 'LANCA Land Use Indicator Value 4054 Calculation in Life Cycle Assessment - Method Report. Fraunhofer Institute for Building Physics.

Beylot, A., Villeneuve, J., 2013. Environmental impacts of residual Municipal Solid Waste incineration: A comparison of 110 French incinerators using a life cycle approach. Waste Manag. 33, 2781-2788. https://doi.org/10.1016/j.wasman.2013.07.003

Boulding, K.E., 1966. The Economies of the Coming Spaceship Earth, in: Environmental Quality in a Growing Economy.

Brunori, G., Galli, F., Barjolle, D., Van Broekhuizen, R., Colombo, L., Giampietro, M., Kirwan, J., Lang, T., Mathijs, E., Maye, D., De Roest, K., Rougoor, C., Schwarz, J., Schmitt, E., Smith, J., Stojanovic, Z., Tisenkopfs, T., Touzard, J.-M., 2016. Are Local Food Chains More Sustainable than Global Food Chains? Considerations for Assessment. Sustainability 8, 449. https://doi.org/10.3390/su8050449

Campbell, B., Beare, D., Bennett, E., Hall-Spencer, J., Ingram, J., Jaramillo, F., Ortiz, R., Ramankutty, N., Sayer, J., Shindell, D., 2017. Agriculture production as a major driver of the Earth system exceeding planetary boundaries. Ecol. Soc. 22. https://doi.org/10.5751/ES-09595-220408

Chance, E., Ashton, W., Pereira, J., Mulrow, J., Norberto, J., Derrible, S., Guilbert, S., 2018. The Plant-An experiment in urban food sustainability. Environ. Prog. Sustain. Energy 37, 82-90. https://doi.org/10.1002/ep.12712

Dorr, E., Sanyé-Mengual, E., Gabrielle, B., Grard, B.J.-P., Aubry, C., 2017. Proper selection of substrates and crops enhances the sustainability of Paris rooftop garden. Agron. Sustain. Dev. 37. https://doi.org/10.1007/s13593-017-0459-1

Ecoinvent, 2018. Ecoinvent LCI Database v. 3.4. 
Edwards-Jones, G., Milà i Canals, L., Hounsome, N., Truninger, M., Koerber, G., Hounsome, B., Cross, P., York, E.H., Hospido, A., Plassmann, K., Harris, I.M., Edwards, R.T., Day, G.A.S., Tomos, A.D., Cowell, S.J., Jones, D.L., 2008. Testing the assertion that 'local food is best': the challenges of an evidence-based approach. Trends Food Sci. Technol. 19, 265-274. https://doi.org/10.1016/j.tifs.2008.01.008

Ekvall, T., Tillman, A.-M., 1997. Open-loop recycling: Criteria for allocation procedures. Int. J. Life Cycle Assess. 2, 155. https://doi.org/10.1007/BF02978810

European Commission, 2020. Circular Economy Action Plan for a cleaner and more competitive Europe. European Commission, 2017. PEFCR Guidance document - Guidance for the development of Product Environmental Footprint Category Rules (PEFCRs), version 6.3.

Fan, W., Zhang, P., Xu, Z., Wei, H., Lu, N., Wang, X., Weng, B., Chen, Z., Wu, F., Dong, X., 2018. Life Cycle Environmental Impact Assessment of Circular Agriculture: A Case Study in Fuqing, China. Sustainability 10, 1810. https://doi.org/10.3390/su10061810

Fassio, F., Tecco, N., 2019. Circular Economy for Food: A Systemic Interpretation of 40 Case Histories in the Food System in Their Relationships with SDGs. Systems 7, 43. https://doi.org/10.3390/systems7030043

Finkbeiner, M., Ackermann, R., Bach, V., Berger, M., Brankatschk, G., Chang, Y.-J., Grinberg, M., Lehmann, A., Martínez-Blanco, J., Minkov, N., Neugebauer, S., Scheumann, R., Schneider, L., Wolf, K., 2014. Challenges in Life Cycle Assessment: An Overview of Current Gaps and Research Needs, in: Klöpffer, W. (Ed.), Background and Future Prospects in Life Cycle Assessment, LCA Compendium - The Complete World of Life Cycle Assessment. Springer Netherlands, Dordrecht, pp. 207-258. https://doi.org/10.1007/978-94-017-8697-3_7

Forssell, S., Lankoski, L., 2015. The sustainability promise of alternative food networks: an examination through "alternative" characteristics. Agric. Hum. Values 32, 63-75. https://doi.org/10.1007/s10460-014-9516-4

Garcia, D.J., You, F., 2016. The water-energy-food nexus and process systems engineering: A new focus. Comput. Chem. Eng., 12th International Symposium on Process Systems Engineering \& 25th European Symposium of Computer Aided Process Engineering (PSE-2015/ESCAPE-25), 31 May - 4 June 2015, Copenhagen, Denmark 91, 49-67. https://doi.org/10.1016/j.compchemeng.2016.03.003

Ghisellini, P., Cialani, C., Ulgiati, S., 2016. A review on circular economy: the expected transition to a balanced interplay of environmental and economic systems. J. Clean. Prod., Towards Post Fossil Carbon Societies: Regenerative and Preventative Eco-Industrial Development 114, 11-32. https://doi.org/10.1016/j.jclepro.2015.09.007

Goedkoop, M., Heijungs, R., Huijbregts, M., De Schryver, A., Struijs, J., van Zelm, R., 2009. ReCiPe 2008, a life cycle impact assessment method which comprises harmonised category indicators at the midpoint and the endpoint level: Characterisation (No. 1). Ministerie can Volkshuisvesting.

Grard, B., Bel, N., Marchal, N., Madre, N., Castell, J.-F., Cambier, P., Houot, S., Manouchehri, N., Besancon, S., Michel, J.-C., Chenu, C., Frascaria-Lacoste, N., Aubry, C., 2015. Recycling urban waste as possible use for rooftop vegetable garden. Future Food J. Food Agric. Soc. 3, 21-34.

Grimm, D., Wösten, H.A.B., 2018. Mushroom cultivation in the circular economy. Appl. Microbiol. Biotechnol. 102, 7795-7803. https://doi.org/10.1007/s00253-018-9226-8

Guinée, J.B., Gorrée, M., Heijungs, R., Huppes, G., Kleijn, R., Koning, A. de, Oers, L. van, Wegener Sleeswijk, A., Suh, S., Udo de Haes, H.A., Bruijn, H. de, Duin, R. van, Huijbregts, M.A.J., 2002. I: LCA in perspective. Ila: Guide. Ilb: Operational annex. III: Scientific background., in: Handbook on Life Cycle Assessment: Operational Guide to the ISO Standards., Eco-Efficiency in Industry and Science. Kluwer Academic Publishers, Dordrecht, p. 692. https://doi.org/10.1007/0-306-48055-7 
764

765

766

767

768

769

770

771

772

773

774

775

776

777

778

779

780

781

782

783

784

785

786

787

788

789

790

791

792

793

794

795

796

797

798

799

800

801

802

803

804

805

806

807

808

809

810
Gunady, M.G.A., Biswas, W., Solah, V.A., James, A.P., 2012. Evaluating the global warming potential of the fresh produce supply chain for strawberries, romaine/cos lettuces (Lactuca sativa), and button mushrooms (Agaricus bisporus) in Western Australia using life cycle assessment (LCA). J. Clean. Prod. 28, 81-87. https://doi.org/10.1016/j.jclepro.2011.12.031

Huijbregts, M.A.J., Steinmann, Z.J.N., Elshout, P.M.F., Stam, G., Verones, F., Vieira, M., Zijp, M., Hollander, A., van Zelm, R., 2017. ReCiPe2016: a harmonised life cycle impact assessment method at midpoint and endpoint level. Int. J. Life Cycle Assess. 22, 138-147. https://doi.org/10.1007/s11367-016-1246-y

International Energy Agency, 2017. France: 2016 Review, Energy Policies of IEA Countries.

IPCC, 2013. Myhre, G., D. Shindell, F.-M. Bréon, W. Collins, J. Fuglestvedt, J. Huang, D. Koch, J.-F., Lamarque, D. Lee, B. Mendoza, T. Nakajima, A. Robock, G. Stephens, T. Takemura and H. Zhang, 2013: Anthropogenic and Natural Radiative Forcing, in: Climate Change 2013 - The Physical Science Basis: Working Group I Contribution to the Fifth Assessment Report of the Intergovernmental Panel on Climate Change. Cambridge University Press, Cambridge, United Kingdom and New York, NY, USA. https://doi.org/10.1017/CBO9781107415324

ISO, 2006. ISO 14044, Environmental management - Life cycle assessment - Requirements and guidelines.

ISO 14040, 2006. Environmental management - Life cycle assessment - Principles and framework. Jurgilevich, A., Birge, T., Kentala-Lehtonen, J., Korhonen-Kurki, K., Pietikäinen, J., Saikku, L., Schösler, H., 2016. Transition towards Circular Economy in the Food System. Sustainability 8, 69. https://doi.org/10.3390/su8010069

Kirchherr, J., Reike, D., Hekkert, M., 2017. Conceptualizing the circular economy: An analysis of 114 definitions. Resour. Conserv. Recycl. 127, 221-232. https://doi.org/10.1016/j.resconrec.2017.09.005

Kiss, K., Ruszkai, C., Takács-György, K., 2019. Examination of Short Supply Chains Based on Circular Economy and Sustainability Aspects. Resources 8, 161. https://doi.org/10.3390/resources8040161

Kloppenburg, J., Hendrickson, J., Stevenson, G.W., 1996. Coming in to the foodshed. Agric. Hum. Values 13, 33-42. https://doi.org/10.1007/BF01538225

Koutrotsios, G., Kalogeropoulos, N., Kaliora, A.C., Zervakis, G.I., 2018. Toward an Increased Functionality in Oyster (Pleurotus) Mushrooms Produced on Grape Marc or Olive Mill Wastes Serving as Sources of Bioactive Compounds. J. Agric. Food Chem. 66, 5971-5983. https://doi.org/10.1021/acs.jafc.8b01532

Kovalcik, A., Obruca, S., Marova, I., 2018. Valorization of spent coffee grounds: A review. Food Bioprod. Process. 110, 104-119. https://doi.org/10.1016/j.fbp.2018.05.002

Krishnan, R., Agarwal, R., Bajada, C., Arshinder, K., 2020. Redesigning a food supply chain for environmental sustainability - An analysis of resource use and recovery. J. Clean. Prod. 242, 118374. https://doi.org/10.1016/j.jclepro.2019.118374

Leiva, F.J., Saenz-Díez, J.C., Martínez, E., Jiménez, E., Blanco, J., 2015a. Environmental impact of Agaricus bisporus cultivation process. Eur. J. Agron. 71, 141-148. https://doi.org/10.1016/j.eja.2015.09.013

Leiva, F.J., Saenz-Díez, J.C., Martínez, E., Jiménez, E., Blanco, J., 2015b. Environmental impact of Agaricus bisporus mycelium production. Agric. Syst. 138, 38-45.

https://doi.org/10.1016/j.agsy.2015.05.003

Llorach-Massana, P., Lopez-Capel, E., Peña, J., Rieradevall, J., Montero, J.I., Puy, N., 2017. Technical feasibility and carbon footprint of biochar co-production with tomato plant residue. Waste Manag. 67, 121-130. https://doi.org/10.1016/j.wasman.2017.05.021 
811

812

813

814

815

816

817

818

819

820

821

822

823

824

825

826

827

828

829

830

831

832

833

834

835

836

837

838

839

840

841

842

843

844

845

846

847

848

849

850

851

852

853

854

855

856
MacArthur, E., Zumwinkel, K., Stuchtey, M.R., 2015. Growth within: a circular economy vision for a competitive Europe. Ellen MacArthur Foundation.

Mairie de Paris, 2017. Paris Circular Economy Action Plan 2017-2020. Paris, France.

Mairie de Paris, 2016. Etat des lieux de l'alimentation à Paris.pdf. Espaces Verts et de l'Environnement: Agence d'Ecologie Urbaine, Paris, France.

Martin, M., Molin, E., 2019. Environmental Assessment of an Urban Vertical Hydroponic Farming System in Sweden. Sustainability 11, 4124. https://doi.org/10.3390/su11154124

Medina, E., Paredes, C., Bustamante, M.A., Moral, R., Moreno-Caselles, J., 2012. Relationships between soil physico-chemical, chemical and biological properties in a soil amended with spent mushroom substrate. Geoderma 173-174, 152-161. https://doi.org/10.1016/j.geoderma.2011.12.011

Merli, R., Preziosi, M., Acampora, A., 2018. How do scholars approach the circular economy? A systematic literature review. J. Clean. Prod. 178, 703-722. https://doi.org/10.1016/j.jclepro.2017.12.112

Mohd Hanafi, F.H., Rezania, S., Mat Taib, S., Md Din, M.F., Yamauchi, M., Sakamoto, M., Hara, H., Park, J., Ebrahimi, S.S., 2018. Environmentally sustainable applications of agro-based spent mushroom substrate (SMS): an overview. J. Mater. Cycles Waste Manag. 20, 1383-1396. https://doi.org/10.1007/s10163-018-0739-0

Mundler, P., Rumpus, L., 2012. The energy efficiency of local food systems: A comparison between different modes of distribution. Food Policy 37, 609-615. https://doi.org/10.1016/j.foodpol.2012.07.006

Murthy, P.S., Madhava Naidu, M., 2012. Sustainable management of coffee industry by-products and value addition-A review. Resour. Conserv. Recycl. 66, 45-58. https://doi.org/10.1016/j.resconrec.2012.06.005

Nemecek, T., Kägi, T., 2007. Life Cycle Inventories of Agricultural Production Systems: Data v2.0 (Ecoinvent Report No. 15). Agroscope Reckenhold-Tänikon Research Station, Zurich, Switzerland.

Notarnicola, B., Salomone, R., Petti, L., Renzulli, P.A., Roma, R., Cerutti, A.K. (Eds.), 2015. Life Cycle Assessment in the Agri-food Sector: Case Studies, Methodological Issues and Best Practices. Springer International Publishing.

Oldfield, T.L., Achmon, Y., Perano, K.M., Dahlquist-Willard, R.M., VanderGheynst, J.S., Stapleton, J.J., Simmons, C.W., Holden, N.M., 2017. A life cycle assessment of biosolarization as a valorization pathway for tomato pomace utilization in California. J. Clean. Prod. 141, 146-156. https://doi.org/10.1016/j.jclepro.2016.09.051

Pagotto, M., Halog, A., 2016. Towards a Circular Economy in Australian Agri-food Industry: An Application of Input-Output Oriented Approaches for Analyzing Resource Efficiency and Competitiveness Potential. J. Ind. Ecol. 20, 1176-1186. https://doi.org/10.1111/jiec.12373

Paredes, C., Medina, E., Moral, R., Pérez-Murcia, M.D., Moreno-Caselles, J., Angeles Bustamante, M., Cecilia, J.A., 2009. Characterization of the Different Organic Matter Fractions of Spent Mushroom Substrate. Commun. Soil Sci. Plant Anal. 40, 150-161. https://doi.org/10.1080/00103620802625575

Pennisi, G., Sanyé-Mengual, E., Orsini, F., Crepaldi, A., Nicola, S., Ochoa, J., Fernandez, J.A., Gianquinto, G., 2019. Modelling Environmental Burdens of Indoor-Grown Vegetables and Herbs as Affected by Red and Blue LED Lighting. Sustainability 11, 4063. https://doi.org/10.3390/su11154063

Robinson, B., Winans, K., Kendall, A., Dlott, J., Dlott, F., 2018. A life cycle assessment of Agaricus bisporus mushroom production in the USA. Int. J. Life Cycle Assess. https://doi.org/10.1007/s11367-018$1456-6$ 
Romeo, D., Vea, E.B., Thomsen, M., 2018. Environmental Impacts of Urban Hydroponics in Europe: A Case Study in Lyon. Procedia CIRP, 25th CIRP Life Cycle Engineering (LCE) Conference, 30 April - 2 May 2018, Copenhagen, Denmark 69, 540-545. https://doi.org/10.1016/j.procir.2017.11.048 Sánchez, C., 2010. Cultivation of Pleurotus ostreatus and other edible mushrooms. Appl. Microbiol. Biotechnol. 85, 1321-1337. https://doi.org/10.1007/s00253-009-2343-7

Sassanelli, C., Rosa, P., Rocca, R., Terzi, S., 2019. Circular economy performance assessment methods: A systematic literature review. J. Clean. Prod. 229, 440-453. https://doi.org/10.1016/j.jclepro.2019.05.019

Schlich, E., Fleissner, U., 2005. The Ecology of Scale: Assessment of Regional Energy Turnover and Comparison with Global Food. Int. J. Life Cycle Assess. 10, 219-223. https://doi.org/10.1065/lca2004.09.180.9

Silvennoinen, K., Heikkilä, L., Katajajuuri, J.-M., Reinikainen, A., 2015. Food waste volume and origin: Case studies in the Finnish food service sector. Waste Manag. 46, 140-145. https://doi.org/10.1016/j.wasman.2015.09.010

Stamets, P., 2000. Growing Gourmet and Medicinal Mushrooms, 3rd ed. Ten Speed Press.

Strazza, C., Magrassi, F., Gallo, M., Del Borghi, A., 2015. Life Cycle Assessment from food to food: A case study of circular economy from cruise ships to aquaculture. Sustain. Prod. Consum., Sustainability issues in the food-energy-water nexus 2, 40-51. https://doi.org/10.1016/j.spc.2015.06.004

Tokimoto, T., Kawasaki, N., Nakamura, T., Akutagawa, J., Tanada, S., 2005. Removal of lead ions in drinking water by coffee grounds as vegetable biomass. J. Colloid Interface Sci. 281, 56-61. https://doi.org/10.1016/j.jcis.2004.08.083

Tóth, G., 2019. Circular Economy and its Comparison with 14 Other Business Sustainability Movements. Resources 8, 159. https://doi.org/10.3390/resources8040159

Ueawiwatsakul, S., Mungcharoen, T., Tongpool, R., 2014. Life Cycle Assessment of Sajor-caju Mushroom (Pleurotus Sajor-caju) from Different Sizes of Farms in Thailand. Int. J. Environ. Sci. Dev. 5, 435439. https://doi.org/10.7763/IJESD.2014.V5.523

U.S. Department of Agriculture, Agricultural Research Service, 2019. FoodData Central.

Vadenbo, C., Hellweg, S., Astrup, T.F., 2017. Let's Be Clear(er) about Substitution. J. Ind. Ecol. 21, 12. https://doi.org/10.1111/jiec.12519

Weber, C.L., Matthews, H.S., 2008. Food-Miles and the Relative Climate Impacts of Food Choices in the United States. Environ. Sci. Technol. 42, 3508-3513. https://doi.org/10.1021/es702969f

Zhang, X.X., Ma, F., Wang, L., 2013. Application of Life Cycle Assessment in Agricultural Circular Economy. Appl. Mech. Mater. 260-261, 1086-1091. https://doi.org/10.4028/www.scientific.net/AMM.260-261.1086 